\title{
Comparative analysis of IKONOS, SPOT, and ETM+ data for leaf area index estimation in temperate coniferous and deciduous forest stands
}

\author{
Kamel Soudani ${ }^{\mathrm{a}, *}$, Christophe François ${ }^{\mathrm{a}}$, Guerric le Maire ${ }^{\mathrm{a}}$, Valérie Le Dantec ${ }^{\mathrm{b}}$, Eric Dufrêne ${ }^{\mathrm{a}}$

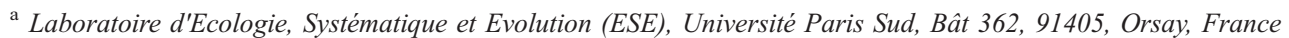 \\ ${ }^{\mathrm{b}}$ Centre Etudes Spatiales de la BIOsphere (CESBIO), (CNES/CNRS/UPS), Toulouse, France
}

\begin{abstract}
The increasing number of sensor types for terrestrial remote sensing has necessitated supplementary efforts to evaluate and standardize data from the different available sensors. In this study, we assess the potential use of IKONOS, ETM+, and SPOT HRVIR sensors for leaf area index (LAI) estimation in forest stands. In situ measurements of LAI in 28 coniferous and deciduous stands are compared to reflectance in the visible, near-infrared, and shortwave bands, and also to five spectral vegetation indices (SVIs): Normalised Difference Vegetation Index (NDVI), Simple Ratio (SR), Soil Adjusted Vegetation Index (SAVI), Enhanced Vegetation Index (EVI), and Atmospherically Resistant Vegetation Index (ARVI). The three sensor types show the same predictive ability for stand LAI, with an uncertainty of about $1.0 \mathrm{~m}^{2} / \mathrm{m}^{2}$ for LAI between 0.5 and $6.9 \mathrm{~m}^{2} / \mathrm{m}^{2}$. For each sensor type, the strength of the empirical relationship between LAI and NDVI remains the same, regardless of the image processing level considered [digital counts, radiances using calibration coefficients for each sensor, top of atmosphere (TOA), and top of canopy (TOC) reflectances]. On the other hand, NDVIs based on radiance, TOA reflectance, and TOC reflectance, determined from IKONOS radiometric data, are systematically lower than from SPOT and ETM+ data. The offset is approximately 0.11 NDVI units for radiance and TOA reflectance-based NDVI, and approximately 0.20 NDVI units after atmospheric corrections. The same conclusions were observed using the other indices. SVIs using IKONOS data are always lower than those computed using ETM+ and SPOT data. Factors that may explain this behavior were investigated. Based on simulations using the SAIL bidirectional canopy reflectance model coupled with the PROSPECT leaf optical properties model (i.e., PROSAIL), we show that the spectral response in radiance of IKONOS sensor in the red band is the main factor explaining the differences in SVIs between IKONOS and the other two sensors. Finally, we conclude that, for bare soils or very sparse vegetation, radiometric data acquired by IKONOS, SPOT, and ETM+ are similar and may be used without any correction. For surfaces covered with dense vegetation, a negative offset of $10 \%$ of IKONOS NDVI should be considered.
\end{abstract}

(C) 2006 Elsevier Inc. All rights reserved.

Keywords: Leaf area index; LAI; NDVI; IKONOS; SPOT-4 HRVIR; Landsat ETM+; Forest; SAIL; PROSPECT

\section{Introduction}

As a result of the great interest in ecological modeling at stand, regional, and global scales, much attention is given to leaf area index (LAI), which is considered to be a key parameter of ecosystem processes (Asner et al., 2003). Various ecophysiological processes of a forest ecosystem are strongly controlled by LAI: interception of light (Machado \& Reich, 1999; Vargas et al., 2002) and precipitation (van Dijk \& Bruijnzeel, 2001),

\footnotetext{
* Corresponding author.

E-mail address: kamel.soudani@ese.u-psud.fr (K. Soudani).
}

gross productivity (Coyea \& Margolis, 1994; Jarvis \& Leverenz, 1983; Linder, 1985; Maguire et al., 1998; Vose \& Allen, 1988), transpiration (Granier et al., 2000), and soil respiration by means of litter return (Davidson et al., 2002; Reichstein et al., 2003).

Since the 1972 launch of the first satellite dedicated to gathering information on earth resources (i.e., Landsat-1), followed by additional satellites from the U.S., Japan, France, and the European Space Agency (ESA) among others, a considerable number of remote sensing images have accumulated. Satellite-derived information is extensively used, and remote sensing has become the primary data source and an 
essential tool for land cover mapping, environmental monitoring, and ecological process scaling from stand to regional and global levels (Plummer, 2000). Available data sets and images archives offer wide possibilities for describing spatial and temporal dynamics of vegetation characteristics over the last 30 years.

The necessity of using data from different satellites in order to obtain a cloud-free image series over an extended period of time raises the issue of the feasibility of using data from different sources. Each remotely sensed satellite image source has its own specifications (orbital altitude, spatial and spectral resolutions, wavelength band limits, relative spectral responses of the sensors, etc.). Radiometric data acquired from different sensors, whether converted or not into spectral vegetation indices (SVIs), are sensor-dependent. They may not be comparable because of differences in the spectral and spatial characteristics of the sensors (Hill \& Aifadopoulou, 1990; Steven et al., 2003; Teillet et al., 1997).

Numerous studies have shown differences between sensors that at first were considered to be similar. Using airborne AVIRIS data (Airborne Visible Infrared Imaging Spectrometer) acquired at 20-m resolution over forest covers, Teillet et al. (1997) tested the sensitivity of the Normalized Difference Vegetation Index (NDVI) to spectral and spatial characteristics of SPOT HRV, Landsat TM, NOAA AVHRR, EOS MODIS, and Envisat MERIS sensors. They showed that the NDVI is significantly affected by differences in spectral bandwidths, especially in the red band. Changes in NDVI due to differences in spatial resolution between sensors depend on the spatial and spectral heterogeneity of the vegetation. In another study, Steven et al. (2003) used simulations to study the effects of sensor spectral characteristics on NDVI. Significant differences were found and the authors established conversion factors for AVHRR, ATSR-2, Landsat MSS, TM, and ETM+, SPOT-2 and SPOT-4 HRV, IRS, IKONOS, SEAWIFS, MISR, MODIS, POLDER, Quickbird, and MERIS sensors.

The increasing number of sensor types has lead to supplementary efforts to evaluate and standardize sensor data (Bricaud et al., 2002; Liang, 2001). SPOT-4 HRVIR (high resolution visible and infrared), Landsat ETM+ (enhanced thematic mapper plus), and IKONOS are among the main commercially available sensors that routinely observe Earth surfaces at high spatial resolution. They constitute the principal data sources for land cover mapping, land use change detection, and forestry assessment and monitoring at regional scales. The sensors also become important sampling devices used for validation of products derived from coarse spatial resolution remote sensing image products, such as MODIS albedo and APAR (Liang et al., 2002), MODIS LAI (Cohen et al., 2003; Wang et al., 2004), tree cover (Hansen et al., 2002), and MODIS GPP/NPP (Turner et al., 2003). Thenkabail (2004) and Goward et al. (2003), particularly, performed inter-sensor comparison studies using IKONOS data. Thenkabail (2004) established among-sensor NDVI relationships for IKONOS and ETM+ data on rainforests and savannas, and observed that IKONOS NDVI was significantly higher than ETM+ NDVI using digital counts and lower using TOA reflectances. Goward et al. (2003) found that IKONOS red and near-infrared reflectances differ between the two sensors, with IKONOS generally producing higher reflectance in the red band, lower reflectance in the nearinfrared band, and lower SR, NDVI, and ARVI than ETM+ for the same vegetation cover characteristics.

There are few studies dealing with the feasibility of using IKONOS, Landsat ETM+, and SPOT-4 HRVIR for the determination of LAI in forest stands, and, as far as we know, there are no studies that have addressed the inter-sensor relationship variations with LAI. For forest applications, studies using data acquired by these three sensors have focused:

(i) On the classification of rain forest vegetation using IKONOS and ETM+ data (Thenkabail et al., 2004). Results showed that IKONOS leads to better classification accuracy than ETM+ data.

(ii) On the estimation of forest stand attributes, such as stand biomass and stem density in central African rainforests using IKONOS and ETM+ data (Thenkabail et al., 2003, 2004), and age class in Douglas-fir stands using texture descriptors derived from IKONOS images (Franklin et al., 2001). Differences between IKONOS and ETM+ were detected, in terms of the predictability of stand biomass and stem density, because of substantial additional information in the SWIR bands of ETM+ (bands 5 and 7) (Thenkabail et al., 2004).

(iii) On LAI estimation using ETM+, IKONOS, and Lidar data (Chen et al., 2004), using only ETM+ data (Eklundh et al., 2001; Cohen et al., 2003; Kalácska et al., 2004) and using only IKONOS data (Colombo et al., 2003).

Our study aims to address these knowledge gaps by investigating the feasibility of using IKONOS, SPOT-4 HRVIR, and Landsat ETM+ images for the determination of LAI in temperate coniferous and deciduous forest stands; by analyzing the effects of the spectral characteristics of these three sensors on the characterization of canopy reflectance behavior in visible and infrared bands, and by establishing inter-sensor relationships over a large range of LAI.

\section{Materials and methods}

\subsection{Study sites}

The test sites are situated in the Fontainebleau Forest, located southeast of Paris, France $\left(48^{\circ} 25^{\prime} \mathrm{N}, 2^{\circ} 40^{\prime} \mathrm{E}\right.$; altitude $\left.120 \mathrm{~m}\right)$. The 17,000-ha mixed deciduous forest is managed by the Office National des Forêts (French national forest service). The climate is temperate, with an average annual temperature of $10.2^{\circ} \mathrm{C}$ and an average annual precipitation of $720 \mathrm{~mm}$. The dominant overstory species are oaks [Quercus petraea and Quercus robur (Matus) Liebl.], beech (Fagus sylvatica L.), and Scots pine (Pinus sylvestris L.). The understory tree species are mainly hornbeam (Carpinus betulus L.) and beech, and the herbaceous species are mainly bramble (Rubus fruticosus L.), brackenfern [Pteridium aquilinum (L.) Kuhn], and purple moor grass [Molinia caerulea (L.)]. Fifty percent of the Fontainebleau 


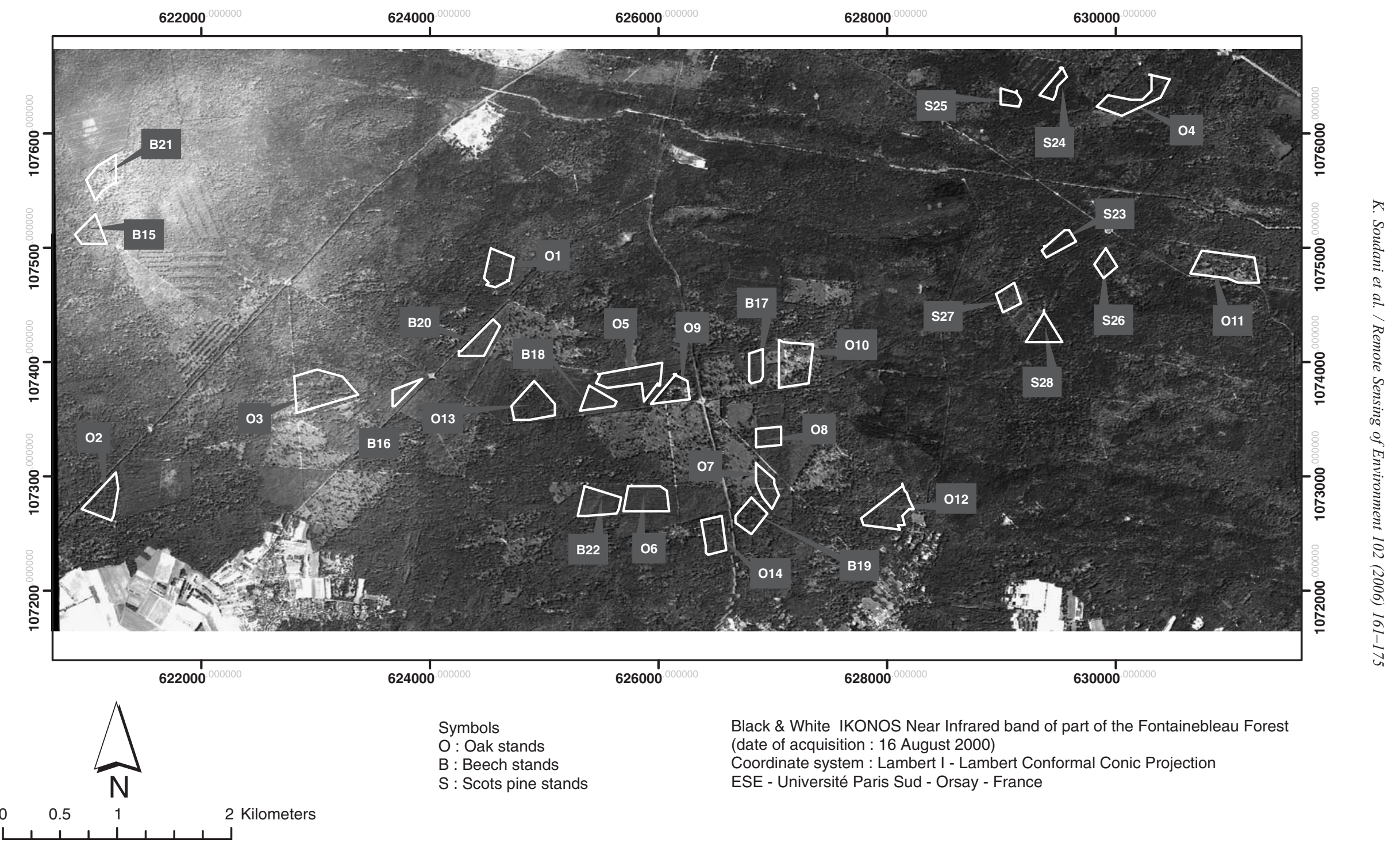

Fig. 1. Locations of the 28 stands sampled within Fontainebleau Forest (O: oak stands, B: beech stands, S: Scots pine stands). The background is a B\&W IKONOS near-infrared band. 
Forest is dominated by oaks, $10 \%$ by beech, and $40 \%$ by Scots pine. In 2000, the growing season began at Julian day 116 (26 April) for both oak and beech. The leaf senescence and fall period ranges from end October to mid-November. The topography is gentle to flat, and soils are on sandy and/or calcareous bedrock. The most frequent types are brunisol, luvisol, and podzol. Humus types vary from mor to mull. The Fontainebleau Forest is described in more detail in le Maire et al. (2005). Twenty-eight forest stands were sampled: 14 occupied by oaks, 6 by Scots pine, and 8 by beech. The area of each stand is between 2 and $13.5 \mathrm{ha}$ ( $5.5 \mathrm{ha}$, on average). Their locations on the forest are given on the IKONOS image (Fig. 1). Main attributes of these stands are given in Table 1. These stands are even-aged and are representative of the different stages of development and stand structure found on the Fontainebleau Forest.

\subsection{Measurements}

Two types of measurements were carried on the 28 stands: ground-based LAI measurements and multi-source satellite data.

\subsubsection{Ground-based LAI measurements}

LAI measurements were made using a ground-based optical instrument, the Plant Canopy Analyser (PCA) LAI-2000 (LI-
COR Inc., Lincoln, NE, USA). A detailed description of this instrument is given in Cutini et al. (1998). LAI was predicted by the standard Poisson model of angular distribution of gap frequency, assuming a random dispersion of leaves in the canopy volume (Nilson, 1971). Gap frequency is given by the ratio of below-canopy to above-canopy radiation, measured for the five zenith angles of the LAI-2000 $\left(0-13^{\circ}, 16-28^{\circ}, 32-43^{\circ}\right.$, $47-58^{\circ}$, and $61-74^{\circ}$ ). Measurements were taken in summer 2000 , from the end of June to the middle of July, under uniform clear diffuse skies at low solar elevation (i.e., for less than $2 \mathrm{~h}$ after sunrise and before sunset). To prevent direct sunlight on the sensor, samples of below- and above-canopy radiation were made in the opposite direction of the sun (i.e., with the sun behind the operator) using a view restrictor of $180^{\circ}$ in the azimuthal plane. Experience shows that measurements under a diffuse overcast sky are questionable because of rapid changes in incident diffuse radiation, especially when only one instrument is used for above- and below-canopy samples, or when two instruments used simultaneously are far from each other. In this study, only one instrument was available and it was used in turn to measure above- and below-canopy radiation. For each stand, reference samples of above-canopy radiation were determined by measuring incoming radiation in an open area (clearings or roads), close to the stand ( $300 \mathrm{~m}$ or less), and sufficiently large to avoid obstructing the field of view of the LAI-2000 for the three upper rings $\left(0-43^{\circ}\right.$ from zenith). For

Table 1

Structural characteristics of the 28 stands sampled

\begin{tabular}{|c|c|c|c|c|c|c|c|c|c|c|}
\hline Stand & $\begin{array}{l}\text { Stand } \\
\text { structure }\end{array}$ & $\begin{array}{l}\text { Main overstory } \\
\text { species }\end{array}$ & $\begin{array}{l}\text { Main understory } \\
\text { species }\end{array}$ & $\begin{array}{l}\text { Stand area } \\
\text { (ha) }\end{array}$ & $\begin{array}{l}\text { Age } \\
\text { (years) }\end{array}$ & $\begin{array}{l}\text { Dominant } \\
\text { height }(\mathrm{m})\end{array}$ & $\begin{array}{l}D \\
\text { (trees/ha) }\end{array}$ & $\begin{array}{l}\mathrm{BA} \\
\left(\mathrm{m}^{2} / \mathrm{ha}\right)\end{array}$ & $\begin{array}{l}\text { Number of LAI } \\
\text { measurements }\end{array}$ & $\begin{array}{l}\text { Stand LAI } \\
\left(\mathrm{m}^{2} / \mathrm{m}^{2}\right)\end{array}$ \\
\hline $\mathrm{O} 1$ & $\mathrm{MF}$ & Oak & Beech & 6.1 & 167 & 30 & 810 & 40.2 & 81 & 3.9 \\
\hline $\mathrm{O} 2$ & $\mathrm{MF}$ & Oak & Beech & 6.6 & 153 & 27 & 1090 & 34.2 & 86 & 5.4 \\
\hline $\mathrm{O} 3$ & MF & Oak & Hornbeam & 13.4 & 156 & 32 & 755 & 35.2 & 69 & 4.4 \\
\hline $\mathrm{O} 4$ & $\mathrm{MF}$ & Oak & - & 7.4 & 93 & 24 & 433 & 25.6 & 144 & 2.5 \\
\hline O5 & SS & Oak & - & 9.1 & $30 *$ & 8.7 & 1988 & 10.5 & 64 & 3.9 \\
\hline O6 & SS & Oak & - & 8.0 & 20 & 8.7 & 4103 & 8.4 & 96 & 4.7 \\
\hline $\mathrm{O} 7$ & SS & Oak & - & 4.3 & $20^{*}$ & 5 & 5984 & 3 & 79 & 4.9 \\
\hline O8 & SS & Oak & - & 3.6 & 24 & 13 & 4872 & 14.4 & 54 & 6.7 \\
\hline O9 & ST & Oak & Beech & 4.6 & 187 & 34 & 518 & 40.8 & 67 & 2.8 \\
\hline O10 & ST & Oak & - & 10.4 & $180^{*}$ & 33 & 71 & 19 & 79 & 0.9 \\
\hline O11 & ST & Oak & - & 11.6 & $180 *$ & 31 & 112 & 15 & 116 & 1.3 \\
\hline $\mathrm{O} 12$ & MF & Oak-beech & Beech & 9.2 & 168 & 34 & 641 & 17.2 & 72 & 5.8 \\
\hline O13 & MF & Oak & Beech-hornbeam & 8.4 & 139 & 32.1 & 1025 & 31.3 & 87 & 4.4 \\
\hline O14 & MF & Oak-beech & Hornbeam & 5.4 & 212 & 29.4 & 297 & 31.3 & 78 & 6.4 \\
\hline B15 & MF & Beech & Beech-hornbeam & 4.3 & 85 & 30 & 639 & 24.1 & 97 & 4.6 \\
\hline B16 & PS & Beech & - & 2.3 & $50 *$ & 18.6 & 2217 & 24.1 & 55 & 5.9 \\
\hline B17 & PS & Beech & - & 4.3 & 50 & 19.9 & 2192 & 21 & 77 & 5.0 \\
\hline B18 & PS & Oak-beech & Hornbeam & 3.8 & 33 & 14.1 & 5053 & 18.1 & 54 & 5.9 \\
\hline B19 & MF & Beech & Beech-hornbeam & 5.0 & 136 & 33.3 & 622 & 32.8 & 46 & 4.3 \\
\hline B20 & PS & Beech & - & 5.4 & 38 & 16 & 3563 & 20.1 & 87 & 6.9 \\
\hline B21 & MF & Beech & - & 5.6 & $100 *$ & 31 & 621 & 21 & 96 & 1.6 \\
\hline B22 & PS & Beech & - & 7.0 & 34 & 14.7 & 4954 & 14.7 & 106 & 5.3 \\
\hline S23 & MF & Scots pine & Beech & 3.2 & 67 & 21 & 1193 & 38.5 & 66 & 3.6 \\
\hline S24 & MF & Scots pine & Beech & 2.5 & 57 & 20 & 557 & 25.9 & 68 & 2.4 \\
\hline S25 & MF & Scots pine & Beech & 2.1 & 90 & 24.3 & 530 & 33.9 & 80 & 2.0 \\
\hline S26 & ST & Scots pine & - & 2.6 & $120 *$ & 22 & 227 & 17 & 65 & 0.7 \\
\hline S27 & ST & Scots pine & - & 3.2 & $120 *$ & 26 & 86 & 13 & 74 & 0.7 \\
\hline S28 & MF & Scots pine & Beech & 4.2 & 108 & 24 & 1041 & 34 & 86 & 2.4 \\
\hline
\end{tabular}

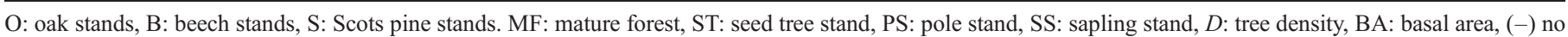
understory, $(*)$ age estimated visually (otherwise, aged by tree cores). 
Table 2

Acquisition dates, and view and sun geometries $(\theta$ : zenithal angle and $\phi$ : azimuthal angle)

\begin{tabular}{lllllcc}
\hline & Date & $\begin{array}{l}\text { Time } \\
\text { UTM }\end{array}$ & $\begin{array}{l}\theta_{\text {sun }} \\
\left({ }^{\circ}\right)\end{array}$ & $\begin{array}{l}\theta_{\text {sun }} \\
\left({ }^{\circ}\right)\end{array}$ & $\begin{array}{l}\theta_{\text {view }} \\
\left({ }^{\circ}\right)\end{array}$ & $\begin{array}{l}\theta_{\text {view }} \\
\left({ }^{\circ}\right)\end{array}$ \\
\hline SPOT4-HRVIR & 21 July 2000 & $11 \mathrm{~h} 09$ & 29.4 & 157.1 & 12.0 & 104.8 \\
Landsat ETM+ & 24 August 2000 & $10 \mathrm{~h} 31$ & 41.4 & 148.91 & 0 & 90 \\
IKONOS & 16 August 2000 & $10 \mathrm{~h} 52$ & 36.85 & 154.88 & 23.62 & 253.3 \\
\hline
\end{tabular}

each stand, several reference samples were taken before, during, and after below-canopy samples. The time between two reference samples was less than $30 \mathrm{~min}$. Depending on stand size, 46 to 144 below-canopy samples were taken at intervals ranging from 5 to $10 \mathrm{~m}$, on at least two transects along the two main diagonals, to obtain a representative measurement of the stand. All below-canopy samples were collected keeping a minimum distance from edges of about two times the maximum tree height to avoid border effects.

Computation of LAI was done using the LI-COR C2000 program (LI-COR, 1992). For each sample of below-canopy radiation, above-canopy radiation was determined by timebased linear interpolation between reference samples. The assumption of linear variation of above-canopy radiation with time at low solar angle elevation was verified for a short time delay (less than $30 \mathrm{~min}$ ) between two samples (Leblanc \& Chen, 2001; Le Dantec et al., 2000). We computed effective LAI according to the methods used in Dufrêne \& Breda (1995) that was carried out on direct measurements and in the same Forest. For broadleaved species, they obtained a better agreement between direct LAI measurements and indirect measurements with LAI-2000 when the two lowest rings $\left(47-58^{\circ}\right.$ and $\left.61-74^{\circ}\right)$ were discarded from the LAI calculation. For broadleaved species, this method of improving LAI estimation using the three upper rings of LAI-2000 has been confirmed by other studies (Olthof \& King, 2000; Soudani et al., 2001; Welles \& Norman, 1991). For coniferous species, the three upper rings were also used to compute LAI because it is easier to find open areas close to the stand to make reference samples.

Stand LAI is calculated as the arithmetic average of all local LAI samples taken within the stand. LAI measured using LAI2000 (or other optical methods) corresponds to plant area index (PAI) including photosynthetic and non-photosynthetic compo- nents (Chen et al., 1997). Note that the underlying assumption of the Poisson model (random dispersion of leaves within the canopy volume) is rarely true in forest canopies. This is particularly the case in coniferous stands where clumping occurs at different spatial scales: within shoots, within crowns, and between trees (Chen et al., 1997; Fournier et al., 1997, 2003; Nilson, 1999; Soudani et al., 2003). Therefore, LAI used here corresponds to effective PAI, neither corrected for clumping nor for the contribution of woody materials (Black et al., 1991; Chen et al., 1997). Nevertheless, for remote sensing applications, LAI as measured by LAI-2000 or other optical methods better describes the leaf surface apparent to a remote sensor (White et al., 1997; Stenberg et al., 2004). Correction for clumping is not absolutely necessary and may be done after regressions with SVIs, as outlined in Stenberg et al. (2004).

\subsubsection{Remote sensing data pre-processing and reflectance estimation}

The remote sensing data have been acquired during the same period of LAI measurements. The acquisition dates and the spatial and spectral characteristics of the images are given in Tables 2 and 3. The spatial resolutions in multispectral mode were $30 \mathrm{~m}, 20 \mathrm{~m}$, and $4 \mathrm{~m}$ for ETM+, SPOT, and IKONOS, respectively.

In order to compute surface reflectance, IKONOS, ETM+, and SPOT images were geometrically and atmospherically corrected. First, the geometric correction was applied to the IKONOS image. Homologous ground control points (GCPs) were selected on the image and on a French National Geographic Institute digital map. Road intersections and bridges over the Seine River served as GCPs. The image rectification was based on a first-order polynomial transformation and the geolocation error was about one pixel $(\sim 4 \mathrm{~m})$. After rectification, the image was radiometrically resampled at its initial spatial resolution using nearest neighbor procedure, and set to the Lambert conformal conic projection and Lambert I coordinate system. Then, this geometrically corrected IKONOS image served as a reference to correct SPOT and ETM+ images, according to the same procedure. The geolocation error of the SPOT and ETM+ was less than one pixel.

In the first step of the atmospheric correction procedure, digital counts (DC) (grey tone) were converted to at-sensor

Table 3

Spectral bandwidths and calibration parameters of the three sensors

\begin{tabular}{|c|c|c|c|c|c|c|c|c|c|c|}
\hline & \multicolumn{3}{|c|}{ Spectral bands $(\mathrm{nm})$} & \multicolumn{4}{|l|}{ Gains } & \multicolumn{3}{|c|}{$\begin{array}{l}\text { Exoatmospheric radiation } \\
\left(\mathrm{W} \mathrm{m}^{-2} \mu \mathrm{m}^{-1}\right)\end{array}$} \\
\hline & ETM+ & SPOT & IKONOS & \multicolumn{2}{|c|}{$\mathrm{ETM}+\left(\mathrm{W} \mathrm{m}^{-2} \mathrm{sr}^{-1} \mu \mathrm{m}^{-1}\right)$} & $\begin{array}{l}\text { SPOT } \\
\left(\mathrm{W}^{-1} \mathrm{~m}^{2} \mathrm{sr} \mu \mathrm{m}\right)\end{array}$ & $\begin{array}{l}\text { IKONOS } \\
\left(\mathrm{W}^{-1} \mathrm{~m}^{2} \mathrm{sr} \mu \mathrm{m}\right)\end{array}$ & ETM+ & SPOT & IKONOS \\
\hline 1. Blue & $450-520$ & - & $445-516$ & -6.2 & 191.6 & - & 63.3 & 1969 & - & 1939 \\
\hline 2. Green & $520-600$ & $500-590$ & $506-595$ & -6.4 & 196.5 & 1.54678 & 64.9 & 1840 & 1843 & 1847 \\
\hline 3. Red & $630-690$ & $610-680$ & $632-698$ & -5 & 152.9 & 1.89702 & 84 & 1551 & 1568 & 1536 \\
\hline 6. SWIR & $2080-2350$ & - & - & -0.35 & 10.8 & - & - & 82.07 & - & - \\
\hline
\end{tabular}

For each band, the IKONOS calibration factors are divided by the bandwidth to express IKONOS spectral radiance in $\mathrm{W} \mathrm{m}^{-2} \mathrm{sr}^{-1} \mu \mathrm{m}^{-1} \mathrm{units}$ 
radiance, $L_{\mathrm{sat}}\left(\mathrm{W} \mathrm{m}^{-2} \mathrm{sr}^{-1} \mu \mathrm{m}^{-1}\right)$, using the gains and offsets given in Goward et al. (2003) for IKONOS sensors and given in image headers for SPOT and ETM+. For SPOT HRVIR and IKONOS sensors, $L_{\text {sat }}$ was calculated using the following relationship:

$L_{\mathrm{sat}}^{i}=\frac{\mathrm{DC}^{i}}{G^{i}}$

where $G^{i}$ is the calibration factor $\left(\mathrm{W}^{-1} \mathrm{~m}^{2} \mathrm{sr} \mu \mathrm{m}\right)$ for the band $i$.

For Landsat ETM + sensors, $L_{\text {sat }}$ was calculated as follows:

$L_{\text {sat }}^{i}=\left(\frac{\mathrm{LMAX}^{i}-\mathrm{LMIN}^{i}}{\mathrm{DCMIN}^{i}-\mathrm{DCMAX}^{i}}\right) \times\left(\mathrm{DC}^{i}-\mathrm{DCMIN}^{i}\right)+\mathrm{LMIN}^{i}$

$\operatorname{LMAX}^{i}$ and $\mathrm{LMIN}^{i}$ are the calibration factors $\left(\mathrm{W} \mathrm{m}^{-2} \mathrm{sr}^{-1}\right.$ $\mu \mathrm{m}^{-1}$ ), and $\operatorname{DCMIN}^{i}$ and $\operatorname{DCMAX}^{i}$ are the minimum and maximum pixel values, respectively. $\operatorname{DCMIN}^{i}=0$ and DCMAX $^{i}=255$ (Landsat-7 Science Data User's Handbook, 2004). $G^{i}, \mathrm{LMIN}^{i}$, and $\mathrm{LMAX}^{i}$ are given in Table 3 for each band $i$ for SPOT, IKONOS, and ETM+.

Then, $L_{\text {sat }}$ was calibrated to scaled surface reflectance after atmospheric corrections using a dark object subtraction (DOS) approach (Song et al., 2001). The DOS approach is a simple and efficient method for atmospheric corrections as shown in previous studies (Brivio et al., 2001; Teillet \& Fedosejevs, 1995; Wang et al., 2004). We preferred to use this approach rather than using radiative transfer models because in the absence of aerosol and water vapour content measurements describing the atmospheric conditions simultaneously to the image acquisitions, performance of radiative transfer models is not guaranteed.

The surface reflectance, $\rho^{i}$, is calculated using the following relationship:

$\rho^{i}=\frac{d^{2} \pi\left(L_{\mathrm{sat}}^{i}-L_{\mathrm{p}}^{i}\right)}{T_{\mathrm{v}}^{i}\left(T_{\mathrm{z}}^{i} E_{0}^{i} \cos \theta_{\mathrm{s}}+E_{\mathrm{down}}^{i}\right)}$

$T_{\mathrm{v}}$ and $T_{\mathrm{z}}$ are the transmittance of the atmosphere in the view and illumination directions, respectively; $E_{\text {down }}^{i}$ is the downwelling diffuse radiation; $E_{0}^{i}$ is the exoatmospheric radiation entering the atmosphere; $\theta_{\mathrm{s}}$ is the sun zenith angle; $d$ is the normalized sun-earth distance when the images were acquired; and $L_{\mathrm{p}}^{i}$ is the path radiance due to atmospheric effects. $L_{\mathrm{p}}^{i}$ is obtained by converting the minimum digital count in each band $i$ into radiance.

$L_{\mathrm{p}}^{i}=L_{\text {sat_min }}^{i}-\frac{0.01\left[E_{0}^{i} \cos \theta_{\mathrm{s}} T_{\mathrm{z}}^{i}+E_{\text {down }}^{i}\right] T_{\mathrm{v}}^{i}}{d^{2} \pi}$

$L_{\text {sat } \min }^{i}$ is the radiance computed using minimum digital count $\left(\mathrm{DC}_{\min }\right)$ in band $i .\left(\mathrm{DC}_{\min }\right)$ is the minimum value of a dark object found in the scene. It is chosen from the histogram of the entire image and corresponds to the DC minimum value from which there is a sharp increase in the number of pixels (Chavez, 1988). $T_{\mathrm{z}}$ and $T_{\mathrm{v}}$ are approximated by the cosine of the solar and view zenith angles, respectively, and this method assumes that there is no diffuse downwelling radiation (Chavez, 1996). The surface reflectance of dark objects is assumed to be equal to $1 \%$ in the red and near-infrared to take into account the radiation scattered by the atmosphere and reflected by the surface (Chavez, 1988, 1996).

Stand reflectance in each band of the three sensors was calculated with ENVI software (Research System Inc., Boulder, CO, USA). First, a vector-based map of sampled stands was created using the map of forest stand polygons available in the Fontainebleau Forest Geographical Information System, and the IKONOS image chosen for its high spatial resolution and accuracy. The limits of each of the 28 stands were vectorised, avoiding $\approx 20 \mathrm{~m}$ from the stand borders to minimize effects of edge and geolocation errors. Then, stand reflectance in each band was calculated as the arithmetic average of reflected radiation of all pixels within the corresponding polygon.

\subsection{SVIs computation and LAI-SVIs regressions analysis}

Average reflectances were used to compute five vegetation indices. These indices are given in Table 4. SR, NDVI, and SAVI are computed using red and near-infrared bands, and are available from the three sensors. EVI and ARVI use the blue band, in addition to red and near-infrared bands, and are computed for IKONOS and ETM + sensors only because there is no blue band from the SPOT HRVIR sensor.

NDVI is the most used vegetation index for a variety of remote sensing applications and it can be computed for all three

Table 4

Spectral vegetation indices NDVI, SR, SAVI, EVI, and ARVI

\begin{tabular}{lll}
\hline Vegetation index & Formulae & \\
$\begin{array}{c}\text { Normalised Difference } \\
\text { Vegetation Index }\end{array}$ & NDVI $=\frac{\rho_{\text {nir }}-\rho_{\text {red }}}{\rho_{\text {nir }}+\rho_{\text {red }}}$ & Rouse and \\
& Haas, 1973
\end{tabular}

Simple Ratio

$$
\mathrm{SR}=\frac{\rho_{\text {nir }}}{\rho_{\text {red }}}
$$

Jordan, 1969

Soil Adjusted

Vegetation Index

$\mathrm{SAVI}=(1+L) \frac{\left(\rho_{\text {nir }}-\rho_{\text {red }}\right)}{\left(\rho_{\text {nir }}+\rho_{\text {red }}+L\right)}$

Huete, 1988

Enhanced Vegetation Index

$$
\mathrm{EVI}=G \frac{\left(\rho_{\text {nir }}-\rho_{\text {red }}\right)}{\left(\rho_{\text {nir }}+C_{1} \rho_{\text {red }}-C_{2} \rho_{\text {blue }}+L\right)} 1994
$$

Atmospherically Resistant

$$
\operatorname{ARVI}=\frac{\left(\rho_{\text {nir }}-\rho_{\text {red }}\right)}{\left(\rho_{\text {nir }}+\rho_{\mathrm{rb}}\right)}
$$

Kaufman \& Tanré, 1992

Vegetation Index

$$
\rho_{\text {rb }}=\rho_{\text {red }}-\gamma\left(\rho_{\text {blue }}-\rho_{\text {red }}\right)
$$

$\rho_{\text {red }}, \rho_{\text {nir }}$, and $\rho_{\text {blue }}$ are red, near-infrared, and blue reflectance, respectively. For the SAVI, $L$ is a canopy background adjustment factor set at 0.5 . For the EVI, $G$, $C_{1}, C_{2}$, and $L$ are coefficients to correct for aerosol scattering, absorption, and background brightness (set at $2.5,6,7.5$, and 1 , respectively). $\gamma$ is a calibration factor set at 1.0. 
sensors; therefore, it was used as the principal basis of comparison between the sensors. Also, because NDVI value depends on the image processing level, it was calculated: (i) using digital counts (grey level), (ii) using at-sensor radiances calibrated according to spectral response of the sensors (Eqs. (1) and (2)), (iii) using TOA reflectances, taking into account variations in the amount of incident radiation due to sun position, or (iv) using above-canopy reflectances, after atmospheric corrections to account for radiation-atmosphere interactions in view and illumination directions.

Empirical relationships between LAI and single bands and SVIs were investigated. Models were fitted and their robustness was evaluated using Pearson's correlation coefficient and root mean square error (RMSE), which corresponds to the square root of the average of the squares of deviations between the measures and the predictions. The statistical analyses were done using Statistica software (Statsoft, Inc., Tulsa, OK, USA).

\subsection{Simulations with PROSAIL}

The radiative transfer model PROSAIL is used to assess if the differences in measured reflectance among the three sensors can be explained by their radiance spectral responses (RSR). Our aim here is not to assess the performance of the PROSAIL model to simulate reflectances. This is why the PROSAIL model is first calibrated on one sensor and then applied to the other sensors: the objective is to see if the RSR alone allows PROSAIL to reproduce the between sensors observed differences.

PROSAIL is a combination of the canopy level bidirectional model SAIL (Scattering by Arbitrarily Inclined Leaves; Verhoef, 1984) without the hotspot effect and the leaf level spectral model PROSPECT (Jacquemoud \& Baret, 1990). The PROSAIL model simulates canopy reflectance in any wavelength in the global radiation spectrum $(0-2500 \mathrm{~nm})$ as a function of (1) canopy and leaf structural parameters-LAI, leaf angle distribution, and leaf mesophyll structure parameter $(N)$; (2) leaf biochemical parameters-chlorophyll $a+b$ concentration $(\mathrm{Cab})$, water content $(\mathrm{Cw})$, and dry matter content $(\mathrm{Cm}) ;(3)$ view and sun geometry parameters - view zenith angle, solar zenith angle, and relative azimuth angle; and (4) soil reflectance.

The RSR of the three sensors in the red and the near-infrared bands are given in Fig. 2a and b. Based on these functions, we calculated the expected reflectance in the red and near-infrared bands using the radiative transfer model PROSAIL.

To take into account the spectral responses of each sensor, the reflectance is calculated as follows:

$R=\frac{\int_{\lambda_{1}}^{\lambda_{2}} \operatorname{RSR}_{\lambda} R_{\text {PROSAIL }} \mathrm{d} \lambda}{\int_{\lambda_{1}}^{\lambda_{2}} \operatorname{RSR}_{\lambda} \mathrm{d} \lambda}$

$\lambda_{1}$ and $\lambda_{2}$ are the band wavelength limits. $R$ is the reflectance simulated by the PROSAIL model $\left(R_{\text {PROSAIL }}\right)$ corrected for the spectral response of the sensor at wavelength $\lambda\left(\mathrm{RSR}_{\lambda}\right)$.

Simulations with the PROSAIL model were done without distinguishing between coniferous and deciduous forest types,
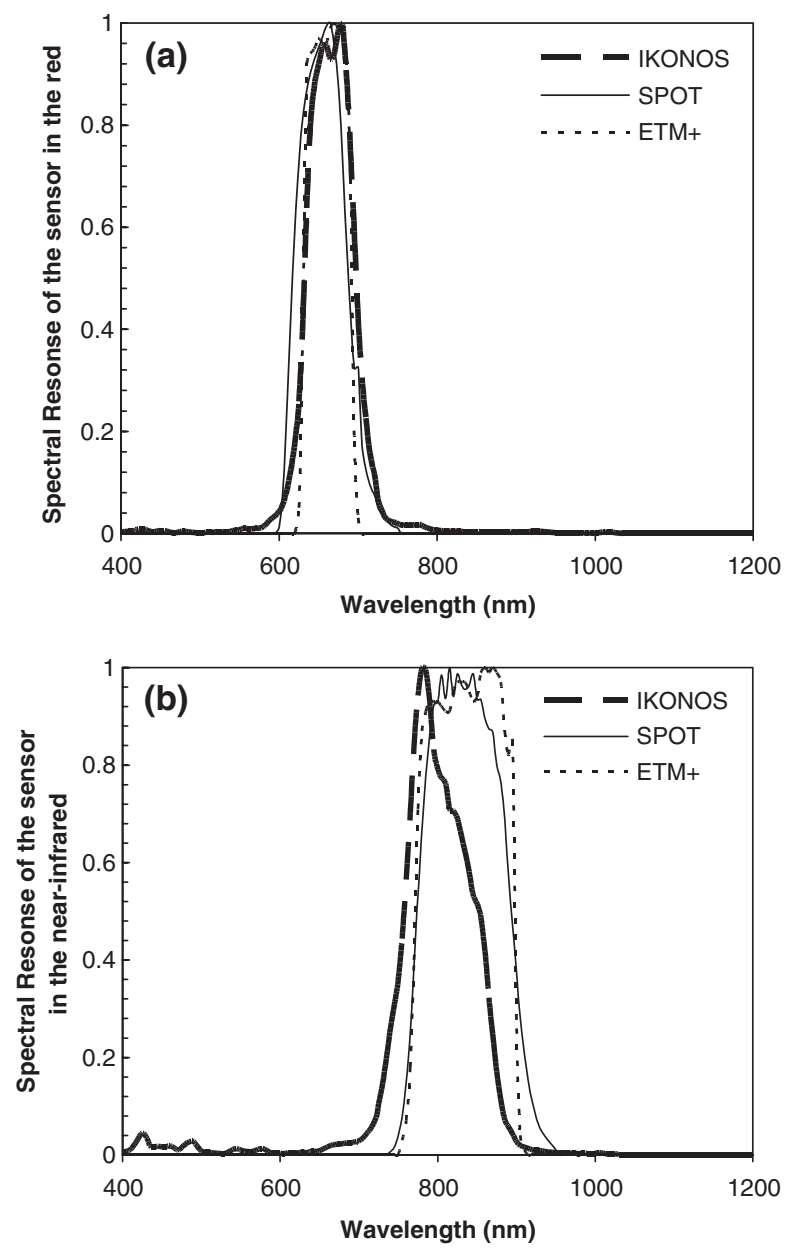

Fig. 2. Spectral responses of IKONOS, SPOT, and ETM+ sensors (a) in the red band and (b) in the near-infrared band.

in accordance with Moorthy et al. (2003) and Zarco-Tejada et al. (2004), who demonstrated the ability of the PROSPECT model to simulate spectral properties of needles.

\section{Results}

\subsection{LAI vs. spectral bands}

The relationships between LAI and reflectance in the red, near-infrared, and SWIR bands are given in Fig. 3a-c. In these figures, the sampled stands were separated in three groups according to the dominant overstory species (Scots pine, beech, and oak) in order to show if they behave in the same manner.

In the red band (Fig. 3a), reflectance of SPOT and ETM+ decrease exponentially with LAI. The Pearson's correlation coefficient is highly significant $(r=-0.75, P<0.001$ for the two sensors), but the predictive ability of this relation is limited to LAI lower than 4 because of the signal saturation for higher LAI. The IKONOS red band shows scattering and there is no significant relationship between this band and LAI $(r=0.02)$.

In the near-infrared band (Fig. 3b), the three sensors show similar behaviors. Reflectance is very scattered but there is a significant correlation between LAI and reflectance for the three 

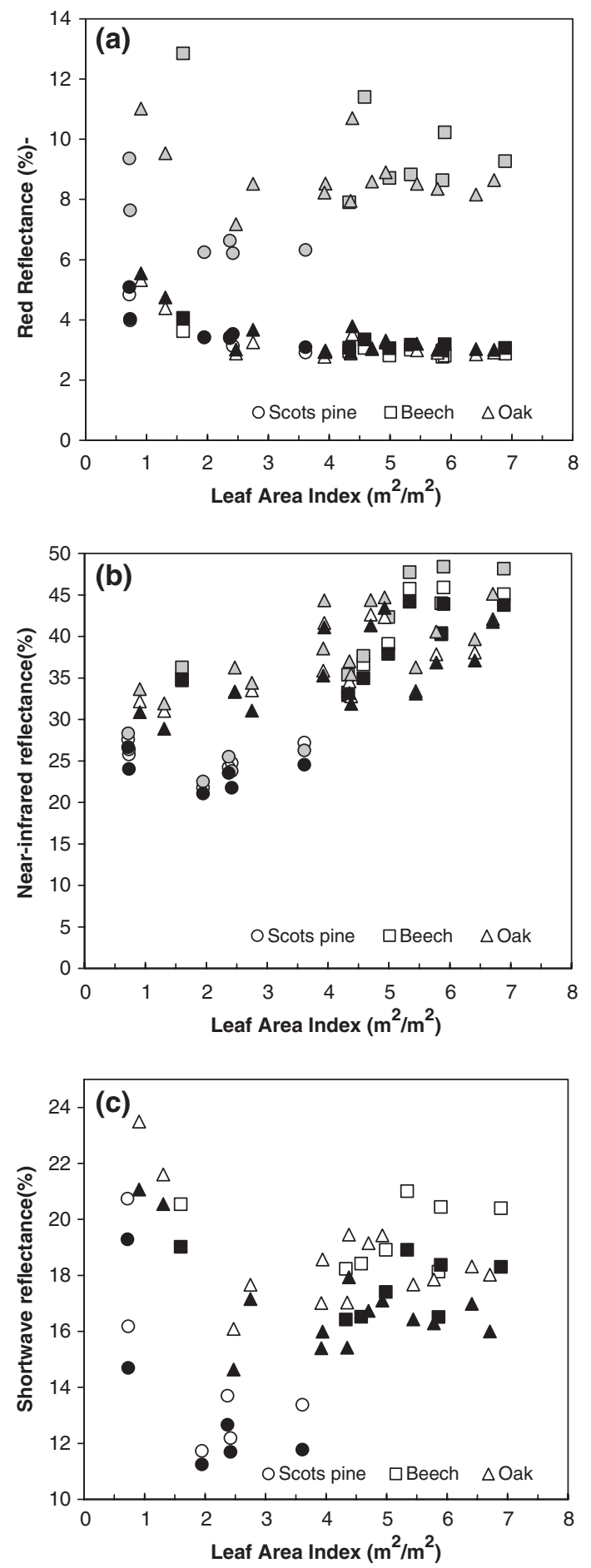

Fig. 3. Reflectance in the red band (a), in the near-infrared band (b), and in the shortwave infrared band (c), vs. leaf area index. Black fill=SPOT, grey fill $=$ IKONOS, no fill $=\mathrm{ETM}+$, circle $=$ Scots pine, square $=$ beech, and triangle $=$ oak

sensors. The Pearson's correlation coefficients are 0.76 $(P<0.001), 0.77(P<0.001)$, and $0.75(P<0.001)$ for $\mathrm{ETM}+$, IKONOS, and SPOT, respectively.

In the SWIR band (Fig. 3c), ETM+ and SPOT show similar behavior. The relationship between LAI and SWIR band reflectance is not statistically significant. If we only take into
Table 5

Average Normalised Difference Vegetation Index (NDVI) using (i) digital counts (without calibration of the sensors), (ii) radiance (after calibration), (iii) top of atmosphere (TOA) reflectance, and (iv) top of canopy (TOC) reflectance

NDVI calculated at different processing levels

\begin{tabular}{lllll}
\hline & Digital count & Radiance & TOA reflectance & TOC reflectance \\
\hline IKONOS & $0.58(0.01)$ & $0.50(0.01)$ & $0.60(0.02)$ & $0.61(0.01)$ \\
SPOT & $0.46(0.02)$ & $0.60(0.02)$ & $0.71(0.01)$ & $0.81(0.01)$ \\
ETM+ & $0.37(0.02)$ & $0.61(0.02)$ & $0.72(0.01)$ & $0.82(0.01)$ \\
\hline
\end{tabular}

The standard error of the mean is given between brackets.

account the deciduous stands, the relationship between LAI and SWIR reflectance is strongly improved. In this case, the Pearson's coefficients are $-0.31(P<0.13)$ for $\mathrm{ETM}+$ and $-0.39(P<0.07)$ for SPOT.

\subsection{LAI vs. SVIS}

Table 5 summarizes the descriptive statistics of canopy NDVI measured by the three sensors for the four image processing levels. Based on digital counts, NDVI values for the three sensors significantly differ. The highest NDVI values are produced by IKONOS. The differences in NDVI values are 0.12 between IKONOS and SPOT, and 0.21 between IKONOS and $\mathrm{ETM}+$. Based on radiances, TOA, and ground reflectances, NDVIs from ETM+ and SPOT are very close. However, the IKONOS NDVI is significantly lower than the other two. The difference in NDVI values between IKONOS and the two other sensors is $\approx 0.11$, using at-sensor radiances. Using atmospherically corrected reflectances, differences between IKONOS and ETM+, and between IKONOS and SPOT are 0.20 and 0.21 , respectively. ETM + and SPOT give very similar average atmospherically corrected NDVI values $(0.82$ and 0.81 , respectively).

Table 6 gives average values of atmospherically corrected red reflectance, near-infrared reflectance, SR, SAVI, ARVI, and EVI for the three sensors. Regardless of the SVI, IKONOS sensors always give the lowest values. Differences between ETM + and SPOT are not statistically significant $(P<0.29$ and $P<0.66$ for SR and SAVI, respectively).

Fig. 4 shows the relationships between NDVI and LAI for the three sensors. All SVI-LAI relationships are positive and they behave similarly. These relationships were fitted to exponential models and, as shown in Table 7, four cases were considered. In the first case, in situ measures of LAI as dependent variables were fitted against corresponding SVI

Table 6

Average SVIs using TOC reflectance for the three sensors

\begin{tabular}{llrr}
\hline & IKONOS & \multicolumn{1}{c}{ SPOT } & \multicolumn{1}{c}{ ETM+ } \\
\hline$\rho_{\text {red }}(\%)$ & $8.05(0.27)$ & $3.45(0.13)$ & $3.27(0.12)$ \\
$\rho_{\text {nir }}(\%)$ & $34.0(1.32)$ & $34.05(1.34)$ & $35.11(1.28)$ \\
SR & $4.23(0.15)$ & $10.30(0.59)$ & $11.19(0.61)$ \\
SAVI & $0.40(0.01)$ & $0.52(0.02)$ & $0.53(0.02)$ \\
ARVI & $0.46(0.02)$ & - & $0.78(0.02)$ \\
EVI & $0.40(0.01)$ & - & $0.58(0.02)$ \\
\hline
\end{tabular}

The standard error of the mean is given between brackets. 


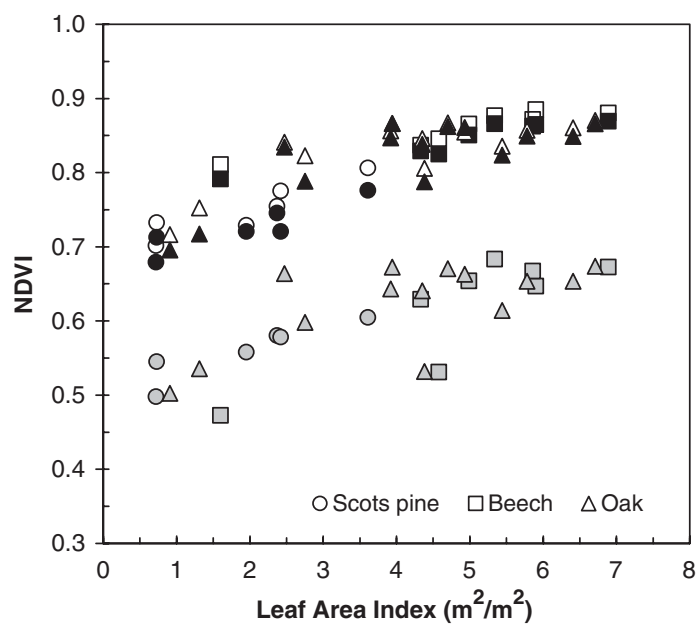

Fig. 4. Normalised Difference Vegetation Index (NDVI) vs. leaf area index. Black fill $=$ SPOT, grey fill $=\mathrm{IKONOS}$, no fill $=\mathrm{ETM}+$, circle $=$ Scots pine, square $=$ beech, and triangle $=$ oak.

values, taking into account the entire range of in situ LAI from 0.7 to $6.9 \mathrm{~m}^{2} / \mathrm{m}^{2}$. In the second case, only LAI values lower than 4 were considered because we suspected a saturation effect on the quality of the model fit. In the third and the fourth cases, fitted relationships between LAI and NDVI were established separately for deciduous and Scots pine stands, but no significant difference appeared between the correlation coefficients (see Section 4).

The Pearson's correlation coefficients and the RMSEs of the LAI-SVI relationships are given in Table 7. Among the four cases considered, using the same pool of stands, no betweensensor differences were significant at the $5 \%$ probability level. RMSE values varied between 0.28 and $1.22 \mathrm{~m}^{2} / \mathrm{m}^{2}$. On average, using the RMSE criterion, ARVI, NDVI, and SR show the same predictive ability for LAI and may be considered to perform better than SAVI and EVI.

To verify whether the deviation between IKONOS and the other two sensors is LAI-dependent, Pearson's correlation coefficient was computed for stand LAI and the difference in stand SVIs between IKONOS and ETM + (or SPOT). In the case of IKONOS and ETM+, the SVI deviation is computed as follows for each stand:

$\mathrm{dSVI}_{\mathrm{ETM} / \mathrm{IKONOS}}=\mathrm{SVI}_{\mathrm{ETM}}-\mathrm{SVI}_{\mathrm{IKONOS}}$

Results showed that the discrepancy between IKONOS and ETM+ (or SPOT) depends on LAI. The highest correlations are between LAI and $\mathrm{dSR}_{\mathrm{ETM} / \mathrm{IKONOS}}(r=0.87, P<0.0001)$, and LAI and $\mathrm{dSR}_{\text {SPOT/IKONOS }}(r=0.86, P<0.0001)$. Pearson's correlation coefficient was also significant between LAI and $\mathrm{dEVI}_{\text {ETM/IKONOS }}(r=0.72, P<0.0001)$, and between LAI and dSAVI SPOT/IKONOS $(r=0.4, P<0.03)$. These results mean that the deviation between IKONOS and the other sensors increases when LAI increases.

\subsection{PROSAIL simulation results}

PROSAIL model calibration was done by visual checking, and by minimizing the square of deviations between ETM + data and a set of PROSAIL simulations in the red and the nearinfrared. The best correspondence between experimental data and model simulations is shown in Fig. 5. Simulations were done with the following input parameters: $N$ (internal structure parameter) $=1.5, \mathrm{Cab}$ (chlorophyll $a+b$ content $=0.5 \mathrm{~g} \mathrm{~m}^{-2}, \mathrm{Cw}$ (water content $)=89 \mathrm{~g} \mathrm{~m}^{-2}, \mathrm{Cm}($ dry matter content $)=92 \mathrm{~g} \mathrm{~m}^{-2}$, LAI ranging from 0 to $8 \mathrm{~m}^{2} / \mathrm{m}^{2}$, spherical leaf angle distribution, mean leaf angle $=30^{\circ}$ from the zenith, view zenith angle $=6^{\circ}$,

Table 7

Nonlinear regressions between LAI and SVI $\left(\mathrm{LAI}=\alpha \mathrm{e}^{\beta \mathrm{SVI}}\right)$

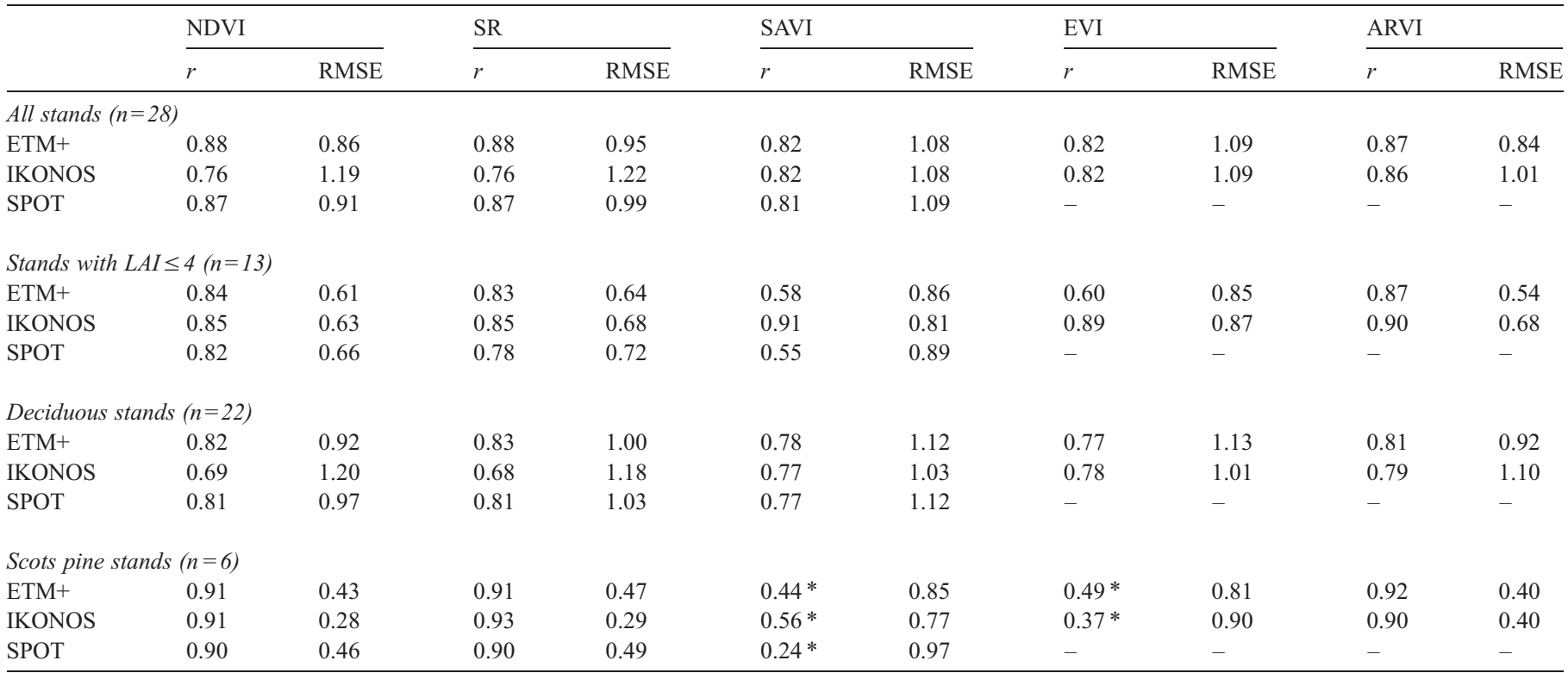

$n$ is the sample size, $r$ is Pearson's correlation coefficient, and RMSE is the root mean square error.

* Not significant at $5 \%$ probability level. 


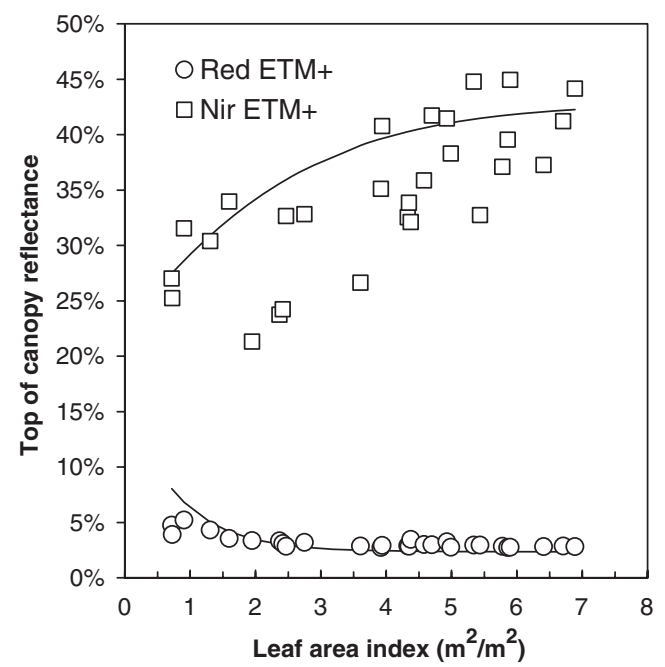

Fig. 5. TOC reflectance measured by ETM+ (a) in the red band and (b) in the near-infrared, vs. leaf area index. Continuous curves represent the simulated reflectance obtained from the PROSAIL model.

and sun zenith angle $=35^{\circ}$. The soil was a wet, dark, grayishbrown, as given in Broge and Leblanc (2001), which corresponds to brunisol soil, the most frequent soil type found in the Fontainebleau Forest.

For LAI ranging from 0 to 8 , reflectances simulated by PROSAIL in the red, near-infrared, and NDVI are given in Fig. $6 \mathrm{a}, \mathrm{b}$, and $\mathrm{c}$ for the three sensors. For measured LAI ranging between 0.7 and $6.9 \mathrm{~m}^{2} / \mathrm{m}^{2}$, IKONOS red reflectance (Fig. 6a) is higher than ETM+ red (4\% vs. 2.6\%) and higher than SPOT red (4\% vs. $3.2 \%$ ). In the near-infrared band (Fig. 6 b), simulated reflectance is lower for the IKONOS than for SPOT or ETM+ (36.6\% vs. $38.6 \%)$. The differences are statistically significant. NDVI is, on average, $0.79,0.87$, and 0.85 for IKONOS, ETM+, and SPOT, respectively (Fig. 6c). For measured LAI between 0.7 and $6.9 \mathrm{~m}^{2} / \mathrm{m}^{2}$, the average offset between IKONOS and $\mathrm{ETM}+$ is $\approx 0.08(10 \%$ of IKONOS NDVI), and $\approx 0.06$ between IKONOS and SPOT ( $8 \%$ of IKONOS NDVI).

As shown in Fig. 6a, b, and c, absolute deviations between IKONOS and the two other sensors increase with LAI in the red and the near-infrared bands. To estimate the sensitivity of NDVI, SR, and SAVI to these deviations, Pearson's correlation coefficient between LAI and dSVI (Eq. (6)) was calculated using the simulations of reflectance. Between IKONOS and the two other sensors, results showed significant positive correlations between LAI and dSVI for the three indices, but the highest correlation coefficient was found between LAI and dSR $(r \approx 0.9)$, followed by dSAVI $(r \approx 0.80)$ and dNDVI $(r \approx 0.5)$. These results from simulations agree with those obtained from the field data (see Section 3.2) and show that SR is more sensitive to differences in spectral properties between the IKONOS sensor and the other two sensors.

The low NDVI values using IKONOS data resulted from higher reflectance in the red band which may be caused by spreading of the tails of the spectral response curve of this sensor, particularly on the right side in the red edge region (Fig. 2a). To confirm this, the spectral response curve of IKONOS sensor was cut off in the red band at $700 \mathrm{~nm}$, precisely at the limit of the ETM+ sensor's spectral response in the red band (the left tail of the spectral response curve from the IKONOS was not modified). The truncated response curve was then used as input to PROSAIL model. As a result, red reflectance for IKONOS decreased from $4.0 \%$ (with the unmodified spectral response) to an average value of $2.7 \%$ for an LAI range of 0.7 to $6.9 \mathrm{~m}^{2} / \mathrm{m}^{2}$. This is practically identical to red reflectance using
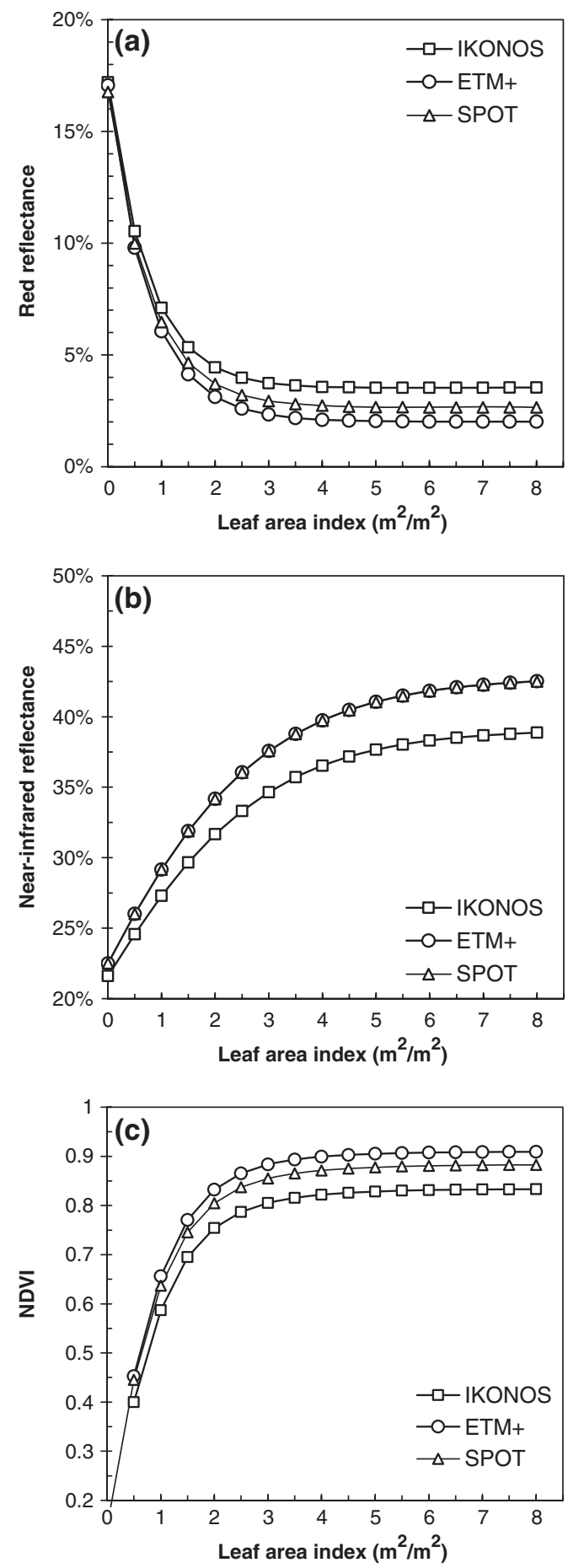

Fig. 6. Relations between leaf area index (LAI) and reflectance from the PROSAIL model for the three sensors: (a) red band reflectance vs. LAI, (b) nearinfrared band reflectance vs. LAI, and (c) NDVI vs. LAI. 
Table 8

Between-sensor calibration factors for the red and near-infrared, and for NDVI

\begin{tabular}{|c|c|c|c|c|c|c|}
\hline & \multicolumn{2}{|l|}{ Red } & \multicolumn{2}{|c|}{ Near-infrared } & \multicolumn{2}{|l|}{ NDVI } \\
\hline & Slope & Intercept & Slope & Intercept & Slope & Intercept \\
\hline vs. ETM+ & 0.941 & -0.025 & 0.8671 & 0.0204 & 0.941 & -0.025 \\
\hline ETM+ vs. IKONOS & 1.0623 & 0.0268 & 1.1532 & -0.0235 & 1.0623 & 0.0268 \\
\hline IKONOS vs. SPOT & 0.9854 & -0.0373 & 0.8687 & 0.0199 & 0.9854 & -0.0373 \\
\hline SPOT vs. IKONOS & 1.0147 & 0.0379 & 1.1512 & -0.0235 & 1.0147 & 0.0379 \\
\hline ETM+ vs. SPOT & 1.047 & -0.0129 & 1.0018 & -0.0005 & 1.047 & -0.0129 \\
\hline SPOT vs. ETM+ & 0.955 & 0.0124 & 0.0005 & 0.9983 & 0.955 & 0.0124 \\
\hline
\end{tabular}

For all regressions, $y$ (dependent variable) versus $x$ (independent variable), $R^{2}>0.98$.

ETM+ (2.6\%). For the same LAI range, the IKONOS NDVI increased from 0.79 (unmodified spectral response) to 0.86 , which is also quite similar to ETM+ NDVI (0.87).

In Table 8, based on PROSAIL simulations for LAI between 0 and 8 , between-sensor calibration factors for the red, the nearinfrared, and the NDVI are given. In all cases, the three sensors show a high degree of correlation $\left(R^{2}>0.98\right)$. The values given in Table 8 are close to the calibration factors calculated for NDVI only in Steven et al. (2003). Maximum differences in slopes and intercepts between our regressions and theirs are 0.0383 and 0.0183 , respectively.

\section{Discussion}

\subsection{Semi-empirical models between LAI and remote sensing data}

The relationships between LAI and the red and the nearinfrared bands shown in Fig. $3 \mathrm{a}$ and $\mathrm{b}$ are similar to those observed in previous studies. These relationships have been verified many times and discussed thoroughly in other studies, based either on radiative transfer models (Baret \& Guyot, 1991; Myneni et al., 1995) or experimental data (Gamon et al., 1995).

The relationship between LAI and the SWIR band was negative for deciduous stands, particularly when SPOT sensors is used $(P<0.07)$ (Fig. 3c). This result agrees with results obtained in other experimental studies (Spanner et al., 1990; Brown et al., 2000) and may be explained by the increase in SWIR absorption by the whole canopy leaf water content when LAI increases. Fig. 3c also shows that, for the same LAI, Scots pine stands (circle symbol) have a lower SWIR reflectance than deciduous stands. Several assumptions may be suggested to explain this behavior. At the leaf scale, the spectral signature of coniferous species shows lower SWIR reflectance than broadleaved species (Williams, 1991; Roberts et al., 2004). At the canopy scale, LAI, as measured in this study, concerns the overstory layer (above $1 \mathrm{~m}$ height) and does not take into account the contribution of herb and shrub layers. These understory layers may be dense in Scots pine stands, which are more open because of foliage clumping, and thus they may contribute significantly to the integrated canopy reflectance (Soudani et al., 2003). The explanations given here are only assumptions and more investigations about the LAI of understory, canopy openness, and clumping are necessary to explain our results.

As shown in Tables 5 and 6, IKONOS SVI values are always lower than those calculated from SPOT and ETM+ data whether at-sensor radiances, TOA reflectances or TOC reflectances are used. Average IKONOS reflectance in the red band is more than double that of SPOT or ETM $+(P<0.0001)$. In the near-infrared band, average reflectance from IKONOS is not statistically different from either ETM+ $(P<0.48)$ or SPOT $(P<0.98)$. Comparing SPOT and ETM+, average red and near-infrared reflectances, as well as the NDVI, are statistically identical $(P<0.3, P<0.57$, and $P<0.37$ in the red, near-infrared, and NDVI, respectively). The higher average in the red band of IKONOS implies a lower average SVI. For example, NDVI calculated using ETM+ is about 0.20 higher than NDVI calculated using IKONOS $(P<0.0001)$.

Relationships between LAI and SVIs (Table 7) show that the three sensors have the same predictive ability when we consider each pool of stands separately. On average, the RMSE values from the different SVIs are very close $\left(\approx 1.0 \mathrm{~m}^{2} / \mathrm{m}^{2}\right)$ for the "all stands" and "deciduous stands" cases. For stands with LAIs less than 4, RMSE value is reduced. RMSE values are also reduced when Scots pine and deciduous stands are taken separately. Lowest RMSE are obtained for Scots pine stands but the difference between the two coefficients of correlation of model fits for "Scots pine" and "deciduous stands" is not statistically significant.

Among the five SVIs, lowest RMSE values are obtained using NDVI, SR, and ARVI $\left(\approx 0.65 \mathrm{~m}^{2} / \mathrm{m}^{2}\right)$. ARVI may be considered the best. For Scots pine stands, results suggested the ARVI, NDVI, and SR also would give the lowest RMSE values; however, the number of stands is too small so the results of model-fitting are inconclusive.

As previously discussed, the higher reflectance in the red band of IKONOS led to negative offsets between IKONOS and both SPOT and ETM+. Application of the ETM+ based LAI-NDVI empirical model, using the TOC average NDVI values from IKONOS, SPOT, and ETM+ sensors (Table 7), gives LAI values of $0.5,3$, and $3.3 \mathrm{~m}^{2} / \mathrm{m}^{2}$, respectively. These results show that the effect of the negative offset of IKONOS NDVI on LAI prediction is very large because of the high sensitivity of the LAI-NDVI models to NDVI variations.

As stated in the introduction, similar findings were observed in other studies. Thenkabail (2004) observed that IKONOS NDVI was higher than ETM+ NDVI when digital counts were used and lower when TOA reflectances were used. Goward et al. (2003) observed an offset of 0.1 for NDVI between ETM+ and IKONOS sensors over different land cover types.

\subsection{Discrepancies among the three sensors}

Numerous factors may explain the discrepancies among the three sensors. In the following sections, we evaluate these factors. Apart from the radiance spectral responses of the sensors, already identified as a main cause of the observed discrepancies, other possible contributing factors are: view, and 
illumination conditions, temporal variations of canopy properties (overstory and understory LAI and chlorophyll content), and atmospheric effects. Effects of differences in spatial resolution among the three sensors are negligible because this study is based on the average reflectance values of stands having an average area of 5.5 ha each.

\subsubsection{Effects of sun-view geometry}

The effects of view and illumination conditions on NDVI were quantitatively evaluated using the PROSAIL model. Reflectance in the red and near-infrared bands and NDVI were computed for the IKONOS sensor for the three geometrical configurations given in Table 2. Results showed that the effects of differences of sun and view angles are negligible. The NDVI values are $0.797,0.795$, and 0.796 for the configurations of IKONOS, SPOT, and ETM+, respectively. These values are very close to the value of 0.79 obtained from the configuration used for the comparison of the three sensors (see Section 3.3).

\subsubsection{Effects of temporal variations of LAI and atmospheric conditions}

In absence of in situ measurements of temporal variations of these factors, we refer in this section to phenological observations in Fontainebleau Forest and findings obtained in other studies.

As reported in Table 2, the three images were acquired in the following order: SPOT (21 July 2000), IKONOS (16 August 2000), and ETM+ (24 August 2000). The time lag between SPOT and ETM+ is about 1 month and about 1 week between IKONOS and ETM+. ETM+ and SPOT give similar SVIs values and the negative offset is only observed between IKONOS and the two other sensors. During the short period of time of about 1 week between IKONOS and ETM+, and even for the longer period of 1 month between IKONOS and SPOT, one can assume that temporal variations of LAI signal are small and cannot explain the differences of SVIs between IKONOS and ETM+ or SPOT. Several studies conducted in different deciduous and coniferous temperate forest stands support the assumption that LAI varies slightly during the vegetation season: from the end of July to the end of August, LAI may be considered as constant in deciduous forest stands (Breda, 2003; Gond et al., 1999; Holst et al., 2004). For Scots pine stands, during the period from the end of June to the end of August, temporal variations of LAI are also small: less than $5 \%$ of maximum LAI in Vose et al. (1994) and practically constant in Gond et al. (1999). This assumption that the LAI does not vary during the peak of the vegetation season is also supported by our phenological observations during several years in the Fontainebleau Forest (unpublished data).

On the given dates (Table 2), the herbaceous understory species, mainly composed of bramble, brackenfern, and purple moor grass, have reached their maximum leaf development, except for bramble which continues to develop secondary branches and stolons until the end of September (Tcherkez, personal communication). Note also that these species are particularly present in open stands whereas the offset between
IKONOS and the three sensors is observed over all LAI range. Concerning the effects of temporal variations of chlorophyll content on remote sensing signal, the works of Blackburn and Milton (1995) and Kodani et al. (2002) in broadleaved forest stands show that NDVI remained relatively stable until late in August.

Considering the short period of 1 week between the dates of acquisition IKONOS and ETM+ images, we can also assume that the temporal variations of LAI understory and the chlorophyll content of the canopy are small and cannot be a major source explaining the differences of SVIs between IKONOS and ETM+.

Concerning the effects of temporal variations of atmospheric conditions between the three image acquisitions, differences among the three sensors were observed at all levels of image processing (Table 5) and through the five spectral indices (Table 6), although ARVI and EVI are designed to be more resistant to atmospheric conditions than SAVI and NDVI (Miura et al., 2001). The ratio TOA NDVI/TOC NDVI is $0.98,0.88$, and 0.87 for IKONOS, SPOT, and ETM+, respectively. This ratio, named NDVI transmissivity in Myneni and Williams (1994), decreases with increasing atmospheric turbidity and solar zenith angle, according to the authors. Based on simulations using different atmospheric optical depths, they also observed that NDVI transmissivity at near-nadir sun position and over dense canopies ranges from 0.8 to 0.9 for turbid to clear atmospheres. Kaufman (1989) reported differences between NDVI at TOC and NDVI at TOA over vegetation covers from 0.2 to 0.37 , which corresponds to ratios between 0.56 and 0.75 over dense canopy with TOC NDVI of 0.8 . In this study, the TOA NDVI/ TOC NDVI ratio for IKONOS exceeded the typical observed values given above, which means that IKONOS TOC NDVI is probably underestimated.

Examination of the IKONOS image (Fig. 1) shows a highly localized presence of cirrus clouds in the western region. Only three stands seem to be situated in this region but we suspect that heterogeneous atmospheric conditions over the sampled sites are not correctly removed by the DOS technique. Indeed, the ratio IKONOS TOA NDVI/TOC NDVI calculated for the 28 stands is significantly correlated with their geographical coordinates $(r=0.79, P<0.0001)$. The slopes of this bilinear regression on north-south and east-west axes are negative, indicating that the atmospheric effects are maximal in the western region and decrease linearly in a southeasterly direction.

The effects of atmosphere-radiation interactions under these conditions are not sufficiently taken into account by the DOS technique (Teillet \& Fedosejevs, 1995) and the effects of the state of the sky cover are difficult to investigate in the absence of in situ measurements of ground reflectance simultaneous with image acquisitions. Several other theoretical weaknesses may also introduce uncertainties in atmospherically corrected NDVI (for more detail, see Hadjimitsis et al., 2004; Teillet \& Fedosejevs, 1995). From a practical point of view, determination of the DC minimum value may be subjected to errors because the choosing of dark object value is made on the basis of visual examination of the histogram (Chavez, 1988). Other 
possible errors in DC minimum value determination are attributable to small image size, errors in the data recording process, noise, and sensor drift (Hadjimitsis et al., 2004). Nevertheless, the DOS technique has made good corrections for atmospheric effects on remote-sensed data, as shown in numerous studies based on reflectance measurements (Brivio et al., 2001; Wang et al., 2004) and simulations (Chavez, 1996; Teillet \& Fedosejevs, 1995).

After atmospheric corrections of SPOT and ETM+ data, the ratios TOA NDVI/TOC NDVI were in the range typically observed, as outlined above. If we assume that the IKONOS TOA NDVI/TOC NDVI ratio should be similar to ratios obtained with SPOT and ETM+, then average IKONOS TOC NDVI would be $\approx 0.7$ (IKONOS TOC NDVI $=$ IKONOS TOA $\mathrm{NDVI} / 0.87)$. Consequently, we conclude that, even after efficient atmospheric corrections, IKONOS TOC NDVI is still lower than that of ETM+ and SPOT. In this case, the offset is -0.12 between IKONOS and ETM+, and -0.11 between IKONOS and SPOT. This is approximately the same as the offset between IKONOS and the other two sensors when radiance and TOA reflectances are used.

\section{Conclusions}

IKONOS, ETM+, and SPOT HRVIR are among the most frequently used sensors for terrestrial applications. Given the subtle responses of canopies to environmental changes, and the small variations of canopy reflectance that are investigated, the intercomparison of these three sensors is an important task that may open new perspectives on spatial and temporal analyses of changes in forest canopies.

Based on in situ measurements of LAI in 28 forest stands, the relationships established between LAI and SVI show that the three sensors have the same ability for LAI prediction. On average, the RMSE values from the different SVIs are very close $\left(\approx 1.0 \mathrm{~m}^{2} / \mathrm{m}^{2}\right)$. On the other hand, SVIs determined using IKONOS radiometric data are systematically lower than those using SPOT and ETM + . The offset is about -0.11 for radiance and TOA reflectance-based NDVI, and about -0.21 after atmospheric corrections. Factors with the potential to explain these differences were evaluated based on simulations using the SAIL bidirectional canopy reflectance model coupled with the PROSPECT leaf optical properties model (i.e., PROSAIL). The analysis showed that:

(a) Using radiance spectral responses from each of three sensors as inputs to the PROSAIL model, IKONOS red reflectance is $53 \%$ higher than SPOT and ETM+. The IKONOS near-infrared band is $5 \%$ lower. The differences in the red band cause an average negative offset of IKONOS NDVI of about 0.08 for LAI ranging from 0.7 to $6.9 \mathrm{~m}^{2} / \mathrm{m}^{2}$. The spectral behavior of ETM+ and SPOT may be considered to be identical.

(b) The gap between IKONOS and both SPOT and ETM+ for red reflectance and NDVI is LAI-dependent. It increases as LAI increases until the signal saturation threshold is reached $\left(\mathrm{LAI} \approx 4 \mathrm{~m}^{2} / \mathrm{m}^{2}\right)$.
Based on PROSAIL simulations, and by truncating the radiance spectral response of the IKONOS red band to match that of ETM+, the discrepancies between the two sensors in the red band and in the NDVI can be largely reduced and the output may be considered similar. It follows from these findings that the edge distortion in the red region of IKONOS spectral response in the red band is the main factor explaining the differences between this sensor and both SPOT and ETM+.

Finally, we conclude that for bare soils or surfaces covered by very sparse vegetation, radiometric data acquired by IKONOS, SPOT, and ETM+ are similar and may be used without any correction. For surfaces with dense vegetation, a negative offset of $10 \%$ of IKONOS NDVIs should be considered.

\section{Acknowledgements}

We would like to express our profound gratitude to the Office National des Forêts for providing us with the GIS database. We also thank ESE members for participating in in situ data collection. We are very grateful for thorough and helpful comments from reviewers of the manuscript.

\section{References}

Asner, G. P., Scurlock, J. M., \& Hicke, J. A. (2003). Global synthesis of leaf area index observations: Implications for ecological and remote sensing studies. Global Ecology and Biogeography, 12, 91-205.

Baret, F., \& Guyot, G. (1991). Potentials and limits of vegetation indices for LAI and APAR assessment. Remote Sensing of Environment, 35, 161-173.

Black, T. A., Lee, X., \& Sagar, R. M. (1991). Characteristics of shortwave and longwave irradiances under a Douglas-fir forest stand. Canadian Journal of Forest Research, 21, 1020-1028.

Blackburn, G. A., \& Milton, E. J. (1995). Seasonal variations in the spectral reflectance of deciduous tree canopies. International Journal of Remote Sensing, 16(4), 709-720.

Breda, N. J. J. (2003). Ground-based measurements of leaf area index: A review of methods, instruments and current controversies. Journal of Experimental Botany, 54(392), 2403-2417.

Bricaud, A., Bosc, E., \& Antoine, D. (2002). Algal biomass and sea surface temperature in the Mediterranean basin: Intercomparison of data from various satellite sensors, and implications for primary production estimates. Remote Sensing of Environment, 81, 163-178.

Brivio, P. A., Giardino, C., \& Zilioli, E. (2001). Determination of chlorophyll concentration changes in Lake Garda using an image-based radiative transfer code for Landsat TM images. International Journal of Remote Sensing, 22, 487-502.

Broge, N. H., \& Leblanc, E. (2001). Comparing prediction power and stability of broadband and hyperspectral vegetation indices for estimation of green leaf area index and canopy chlorophyll density. Remote Sensing of Environment, 76, 156-172.

Brown, L., Chen, J. M., Leblanc, S. G., \& Cihlar, J. (2000). A shortwave infrared modification to the simple ratio for LAI retrieval in boreal forests: An image and model analysis. Remote Sensing of Environment, 71, 16-25.

Chavez, P. S. (1988). An improved dark-object subtraction technique for atmospheric scattering correction of multispectral data. Remote Sensing of Environment, 24, 459-479.

Chavez, P. S. (1996). Image-based atmospheric corrections revisited and revised. Photogrammetric Engineering and Remote Sensing, 62, 1025-1036.

Chen, J. M., Rich, P. M., Gower, S. T., Norman, J. M., \& Plummer, S. (1997), Leaf area index of boreal forests: Theory, techniques and measurements. Journal of Geophysical Research. Atmospheres, 102, 429-443. 
Chen, X., Vierling, L., Rowell, E., \& DeFelice, T. (2004). Using lidar and effective LAI data to evaluate IKONOS and Landsat 7 ETM+ vegetation cover estimates in a ponderosa pine forest. Remote Sensing of Environment, 91, 14-26.

Cohen, W. B., Maiersperger, T. K., Zhiqiang, Y., Gower, S. T., Turner, D. P., Ritts, W. D., et al. (2003). Comparisons of land cover and LAI estimates derived from ETM+ and MODIS for four sites in North America: A quality assessment of 2000/2001 provisional MODIS products. Remote Sensing of Environment, 88, 233-255.

Colombo, R., Bellingeri, D., Fasolini, D., \& Marino, C. M. (2003). Retrieval of leaf area index in different vegetation types using high resolution satellite data. Remote Sensing of Environment, 86, 120-131.

Coyea, M. R., \& Margolis, H. A. (1994). The historical reconstruction of growth efficiency and its relationship to tree mortality in balsam fir ecosystems affected by spruce budworm. Canadian Journal of Forest Research, 24, $2208-2221$.

Cutini, A., Matteucci, G., \& Mugnozza, G. S. (1998). Estimation of leaf area index with the Li-Cor LAI 2000 in deciduous forests. Forest Ecology and Management, 105, 55-65.

Davidson, E. A., Savage, K., Bolstad, P., Clark, D. A., Curtis, P. S., Ellsworth, D. S., et al. (2002). Belowground carbon allocation in forests estimated from litterfall and IRGA-based soil respiration measurements. Agricultural and Forest Meteorology, 113, 39-54.

Dufrêne, E., \& Breda, N. (1995). Estimation of deciduous forest leaf area index using direct and indirect methods. Oecologia, 104, 156-162.

Eklundh, L., Harrie, L., \& Kuusk, A. (2001). Investigating relationships between Landsat ETM+ sensor data and leaf area index in a boreal conifer forest. Remote Sensing of Environment, 78, 239-251.

Fournier, R. A., Daniel, M., Walter, J. -M. N., \& Soudani, K. (2003). Measurement of forest structure. In Mike Wulder, \& Steve Franklin (Eds.), Methods and applications for remote sensing for forests: Concepts and case studies (pp. 77-113). Dordrecht: Kluwer Academic Publishers.

Fournier, R. A., Rich, P. M., \& Landry, R. (1997). Hierarchical characterization of canopy architecture for boreal forest. Journal of Geophysical Research, $102,445-454$.

Franklin, S. E., Wulder, M. A., \& Gerylo, G. R. (2001). Texture analysis of IKONOS panchromatic data for Douglas-fir forest age class separability in British Columbia. International Journal of Remote Sensing, 22, 2627-2632.

Gamon, J. A., Field, C. B., Goulden, M., Griffin, K., Hartley, A., Joel, G., et al. (1995). Relationships between NDVI, canopy structure, and photosynthetic activity in three Californian vegetation types. Ecological Applications, 5, $28-41$.

Gond, V., de Pury, D. G. G., Veroustraete, F., \& Ceulemans, R. (1999). Seasonal variation of leaf-area index, leaf chlorophyll and water content scaled up to fAPAR to estimate the carbon balance of a temperate multi-layer, multispecies forest. Tree Physiology, 19, 673-679.

Goward, S. N., Davis, P. E., Fleming, D., Miller, L., \& Townshend, J. R. (2003). Empirical comparison of Landsat 7 and IKONOS multispectral measurements for selected Earth Observation System (EOS) validation sites. Remote Sensing of Environment, 88, 80-99.

Granier, A., Ceshia, E., Damesin, C., Dufrêne, E., Epron, D., Gross, P., et al. (2000). The carbon balance of a young Beech forest. Functional Ecology, 14, 312-325.

Hadjimitsis, D. G., Clayton, C. R., \& Retalis, A. (2004). On the darkest pixel atmospheric correction algorithm: A revised procedure applied over satellite remotely sensed images intended for environmental applications. In E. Manfred, J. Hermann, \& M. Ulrich (Eds.), Remote sensing for environmental monitoring, GIS applications, and geologyIII Proceedings of SPIE, vol. 5239 (pp. 464-471).

Hansen, M. C., DeFries, R. S., Townshend, J. R. G., Marufud, L., \& Sohlberg, R. (2002). Development of a MODIS tree cover validation data set for Western Province, Zambia. Remote Sensing of Environment, 83, $320-335$.

Hill, J., \& Aifadopoulou, D. (1990). Comparative analysis of Landsat-5 TM and SPOT HRV-1 data for use in multiple sensor approaches. Remote Sensing of Environment, 34, 55-70.
Holst, T., Hauser, S., Kircgäßner, A., Matzarakis, A., Mayer, H., \& Schindler, D. (2004). Measuring and modeling plant area index in beech stands. International Journal of Biometeorology, 48, 192-201.

Huete, A. R. (1988). A soil adjusted vegetation index (SAVI). Remote Sensing of Environment, 25, 295-309.

Huete, A. R., Justice, C., \& Liu, H. (1994). Development of vegetation and soil indices for MODIS-EOS. Remote Sensing of Environment, 49, 224-234.

Jacquemoud, S., \& Baret, B. (1990). PROSPECT: A model of leaf optical properties spectra. Remote Sensing of Environment, 34, 75-91.

Jarvis, P. G., \& Leverenz, J. W. (1983). Productivity of temperate deciduous and evergreen forest. In O. L. Lango, P. S. Nobel, V. B. Osmond, \& H. Ziegler (Eds.), Ecosystem processes: Mineral cycling, productivity and man's influence (pp. 233-280). Berlin: Springer.

Jordan, C. F. (1969). Derivation of leaf area index from quality of light on the forest floor. Ecology, 50, 663-666.

Kalácska, M., Sanchez-Azofeifa, G. A., Rivard, B., Calvo-Alvarado, J. C., Journet, A. R. P., Arroyo-Mora, J. P., et al. (2004). Leaf area index measurements in a tropical moist forest: A case study from Costa Rica. Remote Sensing of Environment, 91, 134-152.

Kaufman, Y. J. (1989). The atmospheric effect on remote sensing and its corrections. In G. Asrar (Ed.), Theory and applications of optical remote sensing (pp. 336-428). New York: Wiley.

Kaufman, Y. J., \& Tanré, D. (1992). Atmospherically Resistant Vegetation Index (ARVI) for EOS-MODIS. IEEE Transactions on Geoscience and Remote Sensing, 30, 261-270.

Kodani, E., Awaya, Y., Tanaka, K., \& Matsumara, N. (2002). Seasonal patterns of canopy structure, biochemistry and spectral reflectance in a broad-leaved deciduous Fagus crenata canopy. Forest Ecology and Management, 167, 233-249.

Landsat-7 Science Data User's Handbook. (2004). NASA/Goddard Space Flight Center, Greenbelt, MD. http://ltpwww.gsfc.nasa.gov/IAS/handbook/ handbook htmls/chapter11/chapter11.html

Leblanc, S. G., \& Chen, J. M. (2001). A practical scheme for correcting multiple scattering effects on optical measurements of leaf area index. Agricultural and Forest Meteorology, 110, 125-139.

Le Dantec, V., Dufrêne, E., \& Saugier, B. (2000). Interannual and spatial variation in maximum leaf area index of temperate deciduous stands. Forest Ecology and Management, 134, 78-81.

le Maire, G., Davi, H., Soudani, K., François, C., Le Dantec, V., \& Dufrêne, E. (2005). Modeling annual production and carbon fluxes of a large managed temperate forest using forest inventories, satellite data and field measurements. Tree Physiology, 25, 859-872.

Liang, S. (2001). Narrowband to broadband conversions of land surface albedo: I. Algorithms. Remote Sensing of Environment, 76, 213-238.

Liang, S., Fang, H., Chen, M., Shuey, C. J., Walthall, C., Daughtry, C., et al. (2002). Validating MODIS land surface reflectance and albedo products: Methods and preliminary results. Remote Sensing of Environment, 83, $149-162$.

LI-COR. (1992). LAI-2000 Plant Canopy Analyser. Operating manual. Li-Cor.

Linder, S. (1985). Potential and actual production in Australian forest stands. In J. J Landsberg, \& W. Parson (Eds.), Research for forest management (pp. 11-35). Melbourne: CSIRO.

Machado, J-L., \& Reich, P. B. (1999). Evaluation of several measures of canopy openness as predictors of photosynthetic photon flux density in deeply shaded conifer-dominated forest understory. Canadian Journal of Forest Research, 29, 1438-1444.

Maguire, D. A., Brissette, J. C., \& Gu, L. (1998). Crown architecture and growth efficiency of red spruce in uneven-aged, mixed species stands in Maine. Canadian Journal of Forest Research, 28, 1233-1240.

Miura, T., Huete, A. R., Yoshioka, H., \& Holben, B. N. (2001). An error and sensitivity analysis of atmospheric resistant vegetation indices derived from dark target-based atmospheric correction. Remote Sensing of Environment, 78, 284-298.

Moorthy, I., Miller, J. R., Noland, T. L., Nielsen, U., \& Zarco-Tejada, P.J. (2003). Needle chlorophyll content estimation of boreal conifers using hyperspectral remote sensing. International Geoscience and Remote Sensing Symposium, IGARSS'03, ISBN 0-7803-7929-2-0-7803-7930-6, Toulouse (France), 21-25/7/2004. 
Myneni, R. B., Maggion, S., Iaquinta, J., Privette, J. L., Gobron, N., Pinty, B., et al. (1995). Optical remote sensing of vegetation: Modelling, caveats and algorithms. Remote Sensing of Environment, 51, 169-188.

Myneni, R. B., \& Williams, D. L. (1994). On the relationship between FAPAR and NDVI. Remote Sensing of Environment, 49, 200-211.

Nilson, T. (1971). A theoretical analysis of the frequency of gaps in plant stands. Agricultural and Forest Meteorology, 8, 25-38.

Nilson, T. (1999). Inversion of gap frequency data in forest stands. Agricultural and Forest Meteorology, 8, 25-38.

Olthof, I., \& King, D. J. (2000). Development of a forest health index using multispectral airborne digital camera imagery. Canadian Journal of Remote Sensing, 26, 166-176.

Plummer, S. E. (2000). Perspectives on combining ecological process models and remotely sensed data. Ecological Modelling, 129, 169-186.

Reichstein, M., Rey, A., Freibauer, A., Tenhunen, J., Valentini, R., Banza, J., et al. (2003). Modelling temporal and large-scale spatial variability of soil respiration from soil water availability, temperature and vegetation productivity indices. Global Biogeochemical Cycles, 17, 1104.

Roberts, D. A., Ustin, S. L., Ogunjemiyo, S., Greenberg, J., Dobrowski, S. Z., Chen, J., et al. (2004). Spectral and structural measures of Northwest forest vegetation at leaf to landscape scales. Ecosystems, 7, 545-562.

Rouse, J. W., \& Haas, R. H. (1973). Monitoring vegetation systems in the great plain with ERTS. Third ERTS Symposium, vol. 1 (pp. 309-317). Washington, DC: NASA.

Song, C., Woodcock, C. E., Seto, K. C., Lenney, P., \& Macomber, S. A. (2001). Classification and change detection using Landsat TM data. When and how to correct atmospheric effects? Remote Sensing of Environment, 75, $230-244$.

Soudani, K., Trautmann, J., \& Walter, J. M. (2001). Comparison of optical methods for estimating canopy openness and leaf area index in broad-leaved forests. Comptes Rendus de l'Académie des Sciences (France), 324, 381-392.

Soudani, K., Trautmann, J., \& Walter, J. -M. N. (2003). Leaf area index and canopy stratification in Scots pine (Pinus sylvestris L.) stands. International Journal of Remote Sensing, 18, 3605-3618.

Spanner, M. A., Pierce, L. L., Peterson, D. L., \& Running, S. W. (1990). Remote sensing of temperate coniferous forest leaf area index: The influence of canopy closure, understory vegetation and background reflectance. International Journal of Remote Sensing, 11, 95-111.

Stenberg, P., Rautiainen, M., Manninen, T., Voipio, P., \& Smolander, Heikki (2004). Reduced simple ratio better than NDVI for estimating LAI in Finnish pine and spruce stands. Silva Fennica, 38(1), 3-14.

Steven, M. D., Malthus, T. J., Baret, F., Xu, H., \& Chopping, M. J. (2003). Intercalibration of vegetation indices from different sensor systems. Remote Sensing of Environment, 88(4), 412-422.

Tcherkez, G. (personal communication). Laboratoire d'Ecologie Systématique et Evolution, Université Paris Sud Orsay (Guillaume.tcherkez@ese.u-psud. fr). Author of-Flowers: Evolution of the floral architecture of angiosperms. Enfield, NH : Science Publishers. 182 pp.

Thenkabail, P. S. (2004). Inter-sensor relationships between IKONOS and Landsat-7 ETM+ NDVI data in three ecoregions of Africa. International Journal of Remote Sensing, 25, 389-408.
Thenkabail, P. S., Enclona, E. A., Ashton, M. S., Legg, C., \& Jean De Dieu, M. (2004). Hyperion, IKONOS, ALI, and ETM+ sensors in the study of African rainforests. Remote Sensing of Environment, 90, 23-43.

Thenkabail, P. S., Hall, J., Lin, T., Ashton, M. S., Harris, D., \& Enclona, E. A. (2003). Detecting floristic structure and pattern across topographic and moisture gradients in a mixed species Central African forest using IKONOS and Landsat-7 ETM+ images. International Journal of Applied Earth Observation and Geoinformation, 4, 255-270.

Teillet, P. M., \& Fedosejevs, G. (1995). On the dark target approach to atmospheric correction of remotely sensed data. Canadian Journal of Remote Sensing, 21, 374-387.

Teillet, P. M., Staenz, K., \& Williams, D. J. (1997). Effects of spectral spatial and radiometric characteristics of remote sensing vegetation indices of forested regions. Remote Sensing of Environment, 61, 139-149.

Turner, D. P., Ritts, W. D., Cohen, W. B., Gower, S. T., Zhao, M., Running, S. W., et al. (2003). Scaling gross primary production (GPP) over boreal and deciduous forest landscapes in support of MODIS GPP product validation. Remote Sensing of Environment, 88, 256-270.

Vargas, L. A., Andersen, M. N., Jensen, C. R., \& Jørgensen, U. (2002). Estimation of leaf area index, light interception and biomass accumulation of Miscanthus sinensis 'Goliath' from radiation measurements. Biomass and Bioenergy, 22, 1-14.

Vose, J. M., \& Allen, H. L. (1988). Leaf area, stemwood growth and nutrition relationships in loblolly pine. Forest Science, 34, 546-563.

Vose, J. M., Dougherty, P. M., Long, J. N., Smith, F. W., Gholz, H. L., \& Curran, P. J. (1994). Factors influencing the amount and distribution of leaf area of pine stands. Ecological Bulletins, 43, 102-114.

Verhoef, W. (1984). Light scattering by leaf layers with application to canopy reflectance modeling: The SAIL model. Remote Sensing of Environment, 16, $125-141$.

Wang, Y., Woodcock, C. E., Buermann, W., Stenberg, P., Voipio, P., Smolander, H., et al. (2004). Evaluation of the MODIS LAI algorithm at a coniferous forest site in Finland. Remote Sensing of Environment, 91, 114-127.

Welles, J. M., \& Norman, J. M. (1991). Instrument for indirect measurement of canopy architecture. Agronomy Journal, 83, 818-825.

White, J. D., Running, S. W., Nemani, R., Keane, R. E., \& Ryan, K. C. (1997). Measurement and remote sensing of LAI in rocky mountain Montana ecosystems. Canadian Journal of Forest Research, 27, 1714-1727.

Williams, D. L. (1991). A comparison of spectral reflectance properties at the needle, branch and canopy level for selected conifer species. Remote Sensing of Environment, 35, 79-93.

van Dijk, A., \& Bruijnzeel, L. A. (2001). Modelling rainfall interception by vegetation of variable density using an adapted analytical model: Part 1. Model description. Journal of Hydrology, 247, 230-238.

Zarco-Tejada, P. J., Miller, J. R., Harro, J., Hu, B., Noland, T. L., Goel, N., et al. (2004). Needle chlorophyll content estimation through model inversion using hyperspectral data from boreal conifer forest canopies. Remote Sensing of Environment, 89, 189-199. 